NBER WORKING PAPER SERIES

\title{
MARKETS FOR ANTHROPOGENIC CARBON WITHIN THE LARGER CARBON CYCLE
}

\author{
Severin Borenstein \\ Working Paper 16104 \\ http://www.nber.org/papers/w16104
}

\author{
NATIONAL BUREAU OF ECONOMIC RESEARCH \\ 1050 Massachusetts Avenue \\ Cambridge, MA 02138
}

June 2010

My thanks to Max Auffhammer, Jim Bushnell, Lucas Davis, Meredith Fowlie, Don Fullerton, Richard Muller, Wolfram Schlenker and Catherine Wolfram for helpful comments and discussions. I am particularly grateful to Margaret Torn for taking the time to explain to me some of the science of the carbon cycle. Any remaining errors are my responsibility alone. The views expressed herein are those of the author and do not necessarily reflect the views of the National Bureau of Economic Research.

NBER working papers are circulated for discussion and comment purposes. They have not been peerreviewed or been subject to the review by the NBER Board of Directors that accompanies official NBER publications.

(C) 2010 by Severin Borenstein. All rights reserved. Short sections of text, not to exceed two paragraphs, may be quoted without explicit permission provided that full credit, including $\odot$ notice, is given to the source. 
Markets for Anthropogenic Carbon Within the Larger Carbon Cycle

Severin Borenstein

NBER Working Paper No. 16104

June 2010

JEL No. H23,Q54

\begin{abstract}
$\underline{\text { ABSTRACT }}$
Human activity has disrupted the natural balance of greenhouse gases in the atmosphere and is causing climate change. Burning fossil fuels and deforestation result directly in about 9 gigatons of carbon (GtC) emissions per year against the backdrop of the natural carbon flux -- emission and uptake -of about $210 \mathrm{GtC}$ per year to and from oceans, vegetation, soils and the atmosphere. But scientific research now indicates that humans are also impacting the natural carbon cycle through less-direct, but very important, mechanisms that are more difficult to monitor and control. I explore the challenges this presents to market or regulatory mechanisms that might be used to reduce greenhouse gases: scientific uncertainty about these indirect processes, pricing heterogeneous impacts of similar human behaviors, and the difficulty of assigning property rights to a far larger set of activities than has previously been contemplated. While this does not undermine arguments for market mechanisms to control direct anthropogenic[release of greenhouse gases, it suggests that more research is needed to determine KRZ and whetherlthese mechanisms can be extended to address indirect human impacts.
\end{abstract}

Severin Borenstein

Haas School of Business

University of California, Berkeley

Berkeley, CA 94720-1900

and NBER

borenste@haas.berkeley.edu 


\section{Introduction}

Among climate scientists, there is a strong consensus that carbon emissions from human activity are increasing atmospheric $\mathrm{CO}_{2}$ concentration and causing climate change. Among economists, there is a strong consensus that the most efficient way to reduce such anthropogenic greenhouse gas emissions is to price them, through either a tax or a tradable permit system. $\mathrm{CO}_{2}$ emissions from burning fossil fuels and deforestation, however, are small compared to the earth's natural carbon flux. These human activities produce about 9 gigatons of carbon ( $\mathrm{GtC}$ ) emissions per year against the natural carbon flux backdrop - emission and uptake - of about $210 \mathrm{GtC}$ per year, to and from oceans, vegetation, soils and the atmosphere. Human activities, however, affect the natural carbon cycle in many ways that have not been incorporated in plans for pricing greenhouse gas emissions. This in no way suggests that human activity is not the primary cause of climate change, but it does suggest that establishing markets and property rights to control these emissions may be more challenging than standard models for tradable pollution permits imply.

In this paper, I explore the implications for pricing carbon emissions when human impacts on the natural carbon cycle are numerous, heterogeneous, and likely to be quantitatively significant beyond the direct greenhouse gas emissions from fossil fuel combustion and deforestation. Because the natural carbon flux between oceans, vegetation, soils, and the atmosphere is so large, even small anthropogenic perturbations in it can significantly alter the impact of human activity on climate. Nearly all of the available economic analysis has treated anthropogenic emissions as a separate and measurable process distinct from the natural carbon cycle. Under certain conditions, this may be a valid approach, but climate science suggests that these condition do not hold and may not even be a good approximation. Thus, it is useful to consider more explicitly the interaction between human activity and the natural carbon cycle, as well as implications for the appropriate boundaries of a market for greenhouse gas emissions.

\section{A Very Brief Review of the Carbon Cycle}

Prior to the mid-19th century when large-scale anthropogenic $\mathrm{CO}_{2}$ emissions began, the oceans, vegetation and soils are estimated to have released about $210 \mathrm{GtC}$ of carbon into the atmosphere in the form of $\mathrm{CO}_{2}$ every year and absorbed the same amount on average. About $90 \mathrm{GtC}$ was transferred to/from the ocean and $120 \mathrm{GtC}$ is transfered to/from vegetation and soils. ${ }^{2}$ Atmospheric levels of $\mathrm{CO}_{2}$ remained in the range of 260-280 parts

2 My characterization of the carbon cycle is based on Houghton (2007), Canadell et al (2007b), and Sarmiento \& Gruber (2002). 
per million (ppm), equivalent to approximately 550-590 GtC in the atmosphere. ${ }^{3}$

Nearly all of these natural processes, however, are affected by changes in atmospheric carbon and the climate. For instance, increases in atmospheric $\mathrm{CO}_{2}$ cause plants to grow faster and absorb more carbon, and cause ocean uptake of carbon to increase; higher average temperatures and other changes in climate alter the rate at which plants decompose and release $\mathrm{CO}_{2}$; and changes in ocean temperature affect its uptake of carbon. Prior to the fossil fuels era, this seems to have been part of the natural resilience of the biosphere that maintained fairly stable atmospheric $\mathrm{CO}_{2}$ concentrations for millenia.

Since the mid-19th century, direct anthropogenic impact on the carbon cycle has steadily increased, primarily through fossil fuel combustion - averaging about 7.6 GtC per year during 2000-2006 - but also through human-caused deforestation and changes in land use - estimated to be about 1.5 GtC per year during 2000-2006. ${ }^{4}$ The deforestation and land use change impacts are known with considerable less certainty than fossil fuel combustion, because the full process of carbon flux between vegetation/soils and the atmosphere is not understood nearly as well as the combustion of oil, coal and natural gas.

Anthropogenic carbon emission must go somewhere. About $45 \%$ shows up as an increase in atmospheric concentration of $\mathrm{CO}_{2}$. Scientists are confident that the residual carbon ends up in vegetation, soils, and the ocean, but attempts to measure these changes directly are imperfect. Carbon is mixed much less uniformly in the ocean than in the atmosphere, so its concentration is more difficult to measure. Concentration in vegetation and soils varies even more and is an even greater measurement challenge. The best estimates are based on widespread sampling of ocean waters to estimate ocean uptake, then attributing the residual to vegetation and soils. This approach suggests that ocean uptake accounts for about $24 \%$ of anthropogenic carbon emissions and $30 \%$ goes to vegetation and soils. However, the processes of ocean and vegetation/soils carbon uptake are not well understood. Estimates of these components - often referred to as the "residual flux," or, somewhat less accurately, the "unidentified sink" - total about 5 GtC per year.

Figure 1 is a simplified representation of the carbon cycle from the U.S. Department of

3 If it were absorbed entirely into the atmosphere, $1 \mathrm{GtC}$ would raise atmospheric level of $\mathrm{CO}_{2}$ by slightly less than $0.5 \mathrm{ppm}$.

4 See Canadell et al (2007b), table 1. The $\mathrm{CO}_{2}$ release attributed to fossil fuels includes the release from heating calcium carbonate in cement production. Non- $\mathrm{CO}_{2}$ forms of carbon in the atmosphere, such as methane, play a significant role in climate change, but are a very small fraction of the carbon cycle. Atmospheric concentration of methane is approximately $1.8 \mathrm{ppm}$. 
Energy, with estimates of the anthropogenic carbon emissions and terrestrial and ocean uptake updated based on figures from Canadell et al (2007b) (in white boxes). While there is some disagreement about the estimates of carbon uptake of vegetation, soils and the ocean, there is widespread agreement that these have been large net carbon sinks over the last two centuries, offsetting a considerable share of the direct anthropogenic carbon emissions.

There is some evidence that the carbon uptake share of non-atmospheric sinks is declining over time, a larger proportion is remaining in the atmosphere. ${ }^{5}$ This suggests that the non-atmospheric sinks, both identified and unidentified, may have started to become saturated. To date, climate change models have handled ocean and terrestrial sinks fairly mechanically, assuming that they will continue to absorb about the same share of anthropogenic carbon as has been estimated from residual sink calculations for recent years, or assuming that the share will change in some gradual and linear way. This is a source of significant uncertainty because both the carbon uptake capacities of these sinks and the impact of human activities on their capacities are not well understood.

\section{Markets for Carbon Emissions}

If the human contribution to atmospheric $\mathrm{CO}_{2}$ were completely distinct from the natural carbon cycle, setting and enforcing a cap on $\mathrm{CO}_{2}$ released from fossil fuel combustion and deforestation would obviously address the carbon cycle imbalance. In that case, reduction of $\mathrm{CO}_{2}$ emissions would translate one-for-one to reductions in atmospheric $\mathrm{CO}_{2}$. From the description of the carbon cycle in the previous section, however, it is clear that this is not at all an accurate representation of the anthropogenic impact.

Apart from burning fossil fuels, most human activity that releases greenhouse gases is interacting with the natural carbon cycle on a short time scale. Cutting a virgin forest likely causes the trees to decompose and release carbon more quickly than would have occurred absent human interaction, in years rather than decades. Human-caused forest fires do so even faster. Agriculture raises many of the same issues, as tilling and crop management alters the soil release and uptake of $\mathrm{CO}_{2}$. Livestock cultivation by humans also disrupts $\mathrm{CO}_{2}$ uptake of soils and vegetation, as well as directly contributing significant quantities of methane. Nitrogen fertilizer, both at the location it is applied by humans and after it migrates through soils and water, interacts with $\mathrm{CO}_{2}$ in complex ways to affect

5 See Le Quéré et al (2009) 
the growth of vegetation and its properties as a carbon sink. ${ }^{6}$ Atmospheric anthropogenic nitrogen also seems likely to be significantly altering the carbon uptake of oceans as well as increasing emissions of nitrous oxide, potentially reducing the net carbon sink impact of oceans by more than half. ${ }^{7}$ Man-made local air pollutants also interact with the natural carbon cycle: tropospheric ozone, a local pollutant created by the chemical interaction of man-made emissions and sunlight, disrupts the carbon sink effect of forests and other vegetation. ${ }^{8}$

Proposals for market mechanisms to control $\mathrm{CO}_{2}$ emissions include restrictions on combustion of all types of fossil fuels, though usually with significant geographic and sectoral limits. Some proposals include limited applications to forestry and agriculture. Through offset programs, inclusion of some additional agriculture and livestock cultivation is often suggested, though it has played an extremely small role in the Clean Development Mechanism. ${ }^{9}$ The impacts of nitrogen fertilization on vegetation, soils and ocean uptake is invariably excluded, as is the impact of local air pollution. Many other ways in which human behavior impacts the natural carbon cycle to exacerbate or reduce atmospheric concentration of $\mathrm{CO}_{2}$ are excluded from the functioning and proposed market mechanisms. The omissions are not because these are understood to be small factors. Some are estimated to be large, though none is estimated very precisely.

\section{Climate feedback effects are a special case of interaction with the natural carbon cycle}

Market mechanisms do not explicitly incorporate aggregate interaction effects, known as feedback effects, in which the total planetary anthropogenic release of greenhouse gases causes changes in the non-anthropogenic carbon flux. Such effects are a function of aggregate anthropogenic emissions because $\mathrm{CO}_{2}$ and other greenhouse gases mix nearly uniformly around the earth's atmosphere: increased atmospheric $\mathrm{CO}_{2}$ concentration causes an increase in the carbon uptake of oceans, vegetation and soils; it contributes directly to higher average temperatures and faster decomposing of dead vegetation which releases more greenhouse gases; higher average temperatures cause faster melting of ice sheets, which then releases methane and also reduces the albedo of the earth. Warming also increases water evaporation and the concentration of atmospheric water vapor, which mag-

\footnotetext{
6 See Reay et al (2008).

7 See Duce et al (2008).

8 See Canadell (2007a).

9 See Grubb et al (2010).
} 
nifies the greenhouse effect. Climate scientists attempt to account for these effects in modeling the relationship between atmospheric greenhouse gases and global temperature changes.

Conceptually these aggregate interactions are straightforward to handle within a market mechanism, though practical application faces substantial uncertainty about the magnitude of their climate impact. If the goal is to stabilize atmospheric carbon at a certain level, aggregate interaction effects would be incorporated into a cap-and-trade program by changing the total direct anthropogenic carbon emissions. The net effect of all aggregate interaction effects would determine a scale parameter, $\theta$, that would change the cap on direct anthropogenic carbon emissions so as to meet the same level of atmospheric carbon as would be the target if $\theta=1$ and there were no interaction effects. A $\theta<1$ would indicate that the natural carbon cycle damps anthropogenic shocks, a net negative feedback effect, and a $\theta>1$ would indicate that it exacerbates the shocks, a net positive feedback effect. The fact that about half of anthropogenic carbon is being absorbed by vegetation, soils, and the ocean suggests a $\theta$ well below one, but acceleration of vegetation decomposing and ice melting indicates the opposite. More importantly, a great deal of uncertainty remains about the longer run $\theta$, though it seems likely to rise if the terrestrial and ocean sinks are becoming saturated and/or melting ice might accelerate the release of greenhouse gases and change the planet's albedo. Nonetheless, for any scientific model of these aggregate interaction effects, the cap on anthropogenic emissions can be adjusted in order to achieve (in expectation) any specified target for atmospheric carbon and climate change. Though the potential scientific impact of feedback effects is quite worrisome, they complicate market mechanisms much less than the idiosyncratic indirect impacts on which I have focused here.

\section{From Incomplete Science to Incomplete Markets and Property Rights}

Market mechanisms to address climate change have been aimed predominantly at reducing the greenhouse gas emissions from burning fossil fuels. Besides the enormous size of the fossil fuels industry, this focus is likely based on the fact that the scientific connection between fossil fuel combustion and greenhouse gas release is well established, and the fact that it is relatively easy to monitor fossil fuel consumption. While it is well understood that human behavior is affecting the natural carbon cycle, those effects are less direct, the relationship is less precisely established, and the emissions are more difficult to monitor. In the last decade, scientists have made important steps in understanding these relationships, but because the impacts are indirect and idiosyncratic it is likely that the links to 
greenhouse gas emissions will never be understood as precisely as the $\mathrm{CO}_{2}$ release from burning a gallon of gasoline. For example, the greenhouse gas impact of nitrogen fertilizer appears to depend very much on where it is used, how it is applied, and how much escapes to neighboring soils and water.

Over time, the challenge of establishing scientific causality will transition to a challenge of establishing markets and property rights for the externalities created. Some empowered institution will have to determine a process for price setting and the initial allocation of the property rights. These appear to be particularly challenging tasks in the case of human impacts on the natural carbon cycle.

The heterogeneity and idiosyncrasy of these indirect impacts will pose a challenge for price setting. Of course, many government-regulated markets face a trade-off between precise cost-based pricing of each sale and the expense of implementing complex pricing schemes. The problem is present in congestion pricing of roads, differentiated time and locational impacts of criteria air pollutants ${ }^{10}$, and time and location varying cost of supplying electricity. In nearly all of these cases, prices vary much less than the underlying economic costs, usually based on appeals to equity and/or simplicity.

Such an outcome could be very inefficient in this case. While science does not yet provide complete answers, it seems likely that the variation in impact on the natural carbon cycle could be enormous for seemingly similar human activities. The impact of agricultural activities, for instance, depends not just on soil composition and alternative land use, but also on the quantities of fertilizers used and their ultimate disposition. Likewise, criteria air pollution has very different impacts on the natural carbon cycle depending on where the pollution is released. Due to the interaction with the natural carbon cycle, it seems quite possible that an activity could raise greenhouse gases if undertaken in some locations and lower it if the same activity is undertaken in other locations.

The idiosyncrasy of human impacts on the natural carbon cycle is also likely to greatly increase the complexity of allocating property rights and monitoring outcomes. Indirect impacts on the natural carbon cycle are likely to be difficult to monitor by their very nature, and large variation in impact from seemingly similar activities will make simplifying approaches less reliable - for example, a standard assumption about the carbon impact of releasing one pound of atmospheric nitrogen. Likewise, because property rights allocation will be concerned with distributional issues, difficulty in determining a participant's prob-

10 See Tietenberg (1995). 
able liability under a proposed price schedule could slow the political process and raise costs.

Scientific uncertainty is also likely to compound the difficulties of reaching agreements on property rights. Previous debates over the costs of environmental degradation - health impacts of criteria air pollutants, ozone depletion caused by CFCs, and fossil fuels causing climate change - suggest that potential losers in the allocation of property rights will appeal to residual scientific uncertainty as a reason to postpone creation of the market. Indirect impacts on the natural carbon cycle seem likely to be particularly vulnerable to these delay strategies. ${ }^{11}$

Ultimately, the value of incorporating human impact on the natural carbon cycle as part of carbon markets also depends on the potential for price incentives to change that interaction. In this dimension, it seems that the value is likely to be high. The human activities that science has already identified - including land management, use of nitrogen fertilizers, and control of criteria air pollutants - are generally thought to be responsive to economic incentives, certainly likely to be as responsive as energy demand. These are empirical questions, however, that remain to be addressed.

\section{Can carbon offsets better address interactions with the natural carbon cycle?}

The effects that I am discussing here are similar in practice to excluding a sector of the economy, or region of the world, under cap-and-trade. Carbon offsets are often presented as a way to reduce emissions from an excluded sector or region, as described by Bushnell in another chapter of this volume. But the political, jurisdictional and distributional concerns that give rise to sectoral or regional exclusion are not the primary impediments to incorporating interactions with the natural carbon cycle. Rather, uncertain science and costly monitoring of the human behavior that causes the interaction have led to the exclusion of these emissions from market mechanisms. Carbon offsets do not address either of these problems. If these barriers were remediated, policy makers still might run into the concerns that are addressed by carbon offsets depending on the location of the activity and people involved in it. There is, however, no obvious reason to think that the range of human activities that constitute interaction with the natural carbon cycle are more amenable to control through carbon offsets than through direct inclusion in a market mechanism such

11 Recent arguments over life-cycle analyses of petroleum products and corn-based ethanol in California, including the impact of indirect land-use changes, are certainly consistent with this view. The parties that would have been harmed by recognizing indirect land-use effects argued that because considerable uncertainty about their magnitude existed, they should be counted as zero. 
as cap-and-trade or a carbon tax.

\section{Conclusion}

Climate scientists have determined that many different human activities impact the levels of atmospheric greenhouse gases, not just burning fossil fuels. Many of these interactions are not well understood, but they are almost surely both heterogeneous and important in addressing climate change. Recent research suggests that human-caused air pollution, fertilizer dispersion, soil disruption, and other activities are having a significant effect on the net carbon uptake of vegetation, soils and oceans. To date, market mechanisms for reducing greenhouse gases have largely ignored these interactions between human activity and the natural carbon flux.

My goal in this paper is to argue that the scientific research on these interactions has matured to the point that it is time for economists and policy makers to take note, to consider whether market mechanisms for greenhouse gases need to be extended to incorporate these complexities. Such extensions would be very challenging. The heterogeneity and idiosyncrasy of human impact on the natural carbon cycle would make appropriate pricing quite difficult, and the remaining scientific uncertainty about these interactions would likely impede efforts to assign property rights. Addressing some interactions would require determining property rights for a much broader range of activities than has ever before existed.

The costs of extending carbon markets in this direction must be weighed against the potential benefits. The benefits will depend on the magnitude of the interaction effects, which is the domain of natural scientists, and the price elasticities of the human activities that cause them, the determination of which should be economists' comparative advantage.

Finally, while I have focused here on market mechanisms - taxes or tradeable permits the same concerns of heterogeneous and idiosyncratic interactions with the natural carbon

cycle would apply to any attempt to address greenhouse gases with command and control regulation. Just as many more prices and property rights determinations are needed in a market setting due to indirect impacts on the natural carbon cycle, many more regulations would be needed under a command and control approach. 


\section{References}

Bushnell, James B. "The Economics of Carbon Offsets," in Don Fullerton \& Catherine Wolfram eds., The Design and Implementation of U.S. Climate Policy, University of Chicago Press, forthcoming.

Canadell, Josep G., Miko U.F. Kirschbaumb, Werner A. Kurz, María-José Sanz, Bernhard Schlamadinger, and Yoshiki Yamagata. "Factoring out natural and indirect human effects on terrestrial carbon sources and sinks," Environmental Science $6 \mathcal{F}$ Policy, Vol. 10, 2007(a), pp. 370-384.

Canadell, Josep G., Corinne Le Quéré, Michael R. Raupach, Christopher B. Field, Erik T. Buitenhuis, Philippe Ciais, Thomas J. Conway, Nathan P. Gillett, R. A. Houghton, and Gregg Marlandi. "Contributions to accelerating atmospheric $\mathrm{CO}_{2}$ growth from economic activity, carbon intensity, and efficiency of natural sinks," Proceedings of the National Academy of Sciences, Vol. 104(47), November 20, 2007(b), pp. 18866-18870.

Duce, R. A. et al. "Impacts of atmospheric anthropogenic nitrogen on the open ocean," Science, Vol. 320, 2007, pp. 893897.

Grubb, Michael, Tim Laing, Thomas Counsell, and Catherine Willan. "Global carbon mechanisms: lessons and implications," Climatic Change, 16 January 2010.

Houghton, R.A. "Balancing the Global Carbon Budget," Annual Review of Earth and Planetary Sciences, Vol. 35, 2007, pp. 313-347.

Le Quéré, Corinne, Michael R. Raupach, Josep G. Canadell, Gregg Marland et al. "Trends in the sources and sinks of carbon dioxide," Nature Geoscience, Vol. 2, December 2009, pp. 831-836.

Reay, Dave S., Frank Dentener, Pete Smith, John Grace and Richard A Feely. "Global nitrogen deposition and carbon sinks," Nature Geoscience, Vol. 1, July 2008, pp. 430437.

Sarmiento, Jorge L. and Nicolas Gruber. "Sinks for Anthropogenic Carbon," Physics Today, Vol. 55(8), 2002, pp. 30-36.

Tietenberg, Tom. "Tradeable Permits for Pollution Control when Emission Location Matters: What have We Learned?" Environmental and Resource Economics, Vol. 5, 1995, pp. 95-113.

Wara, Michael W. and David G. Victor, "A Realistic Policy on International Carbon Offsets," PESD Working Paper \#74, Stanford University, 2008. 


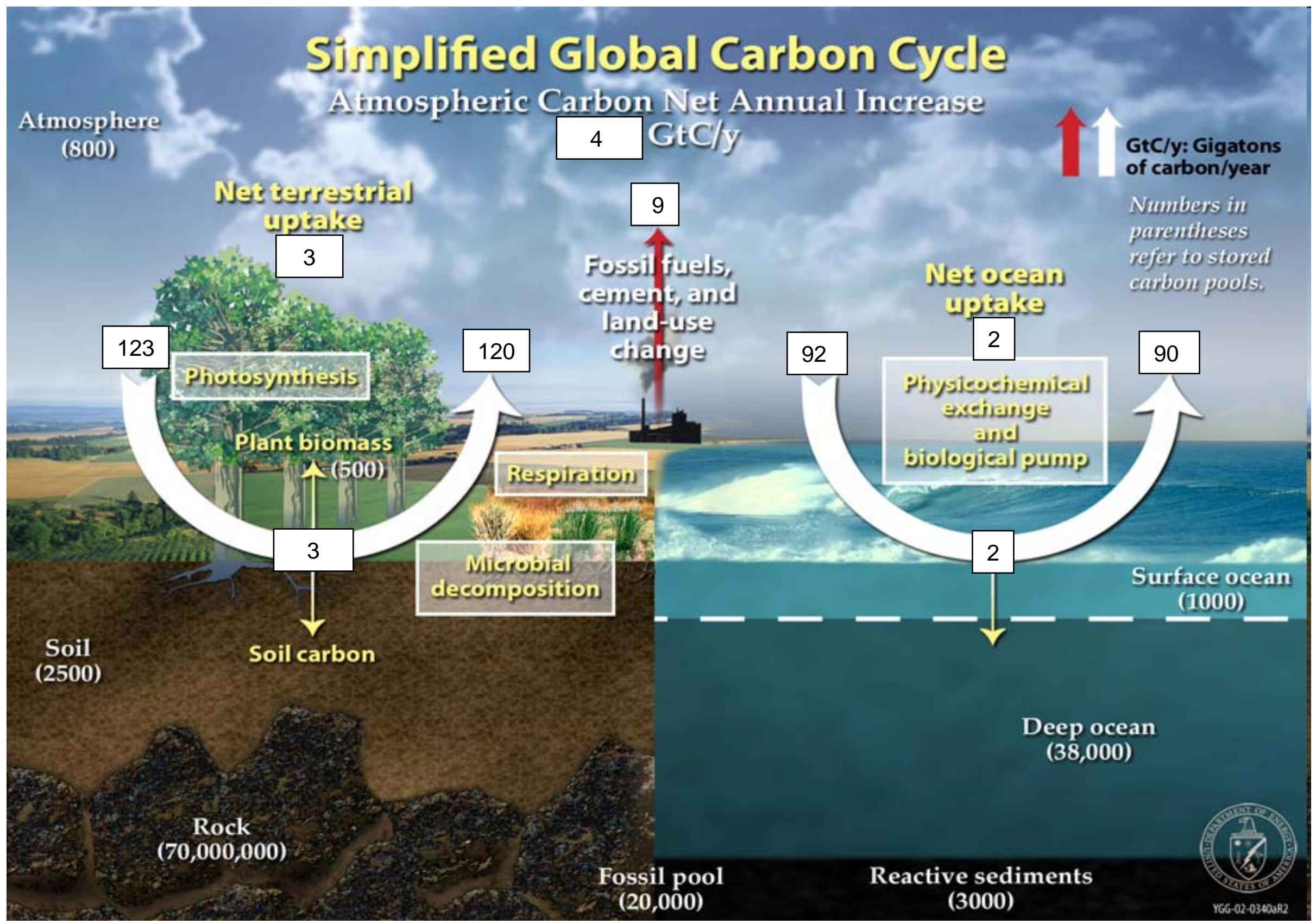

Figure 1

(source: U.S. Department of Energy and Canadell et al (2007b)) 